\title{
A Unique Ectonucleotide Pyrophosphohydrolase Associated with Porcine Chondrocyte-derived Vesicles
}

Ikuko Masuda, ${ }^{\star}$ Jun-ichiro Hamada, ${ }^{*}$ Arthur L. Haas, ${ }^{\ddagger}$ Lawrence M. Ryan, ${ }^{\star}$ and Daniel J. McCarty*

*The Division of Rheumatology, Department of Medicine, and ${ }^{\ddagger}$ Department of Biochemistry, Medical College of Wisconsin,

Milwaukee, Wisconsin 53226

\section{Abstract}

Previous studies have shown increased nucleotide pyrophosphohydrolase (EC 3.6.1.8) (NTPPHase) activity in detergent extracts of degenerated human cartilage containing calcium pyrophosphate dihydrate (CPPD) crystals relative to those from osteoarthritis or normal cartilage. NTPPHase was later shown to be an ectoenzyme and its activity was increased in synovial fluid from patients with CPPD crystal deposits relative to fluids from other types of arthritis. We have purified a soluble 61-kD NTPPHase from conditioned media of organ-cultured porcine articular cartilage to electrophoretic homogeneity. Its $\mathbf{N H}_{2}$-terminal sequence through 26 cycles showed $<30 \%$ homology to any previously reported protein sequence. An antibody raised to a synthetic peptide corresponding to this sequence reacted with denatured but not native enzyme. This antibody reacted against a sedimentable vesicle-associated $127-\mathrm{kD}$ protein in conditioned media from cultured articular cartilage or from chondrocytes in primary monolayer culture and against a series of soluble proteins in conditioned media supernatant, including a $61-\mathrm{kD}$ protein representing our original isolate. No reactivity was found in 1\% SDS extracts of washed cultured chondrocytes, although these contained greater NTPPHase activity than the conditioned media. Antibody to PC-1, another ectoNTPPHase, reacted with $1 \%$ SDS extracts of whole chondrocytes but not against those chromatographic fractions containing the major portion of NTPPHase activity. Release of the vesicle-associated 127-kD enzyme into conditioned medium was stimulated three- to sevenfold by TGF $\beta_{1}$. The antibody also reacted with a series of soluble proteins and with a 127-kD sedimentable protein in human synovial fluid. Kinetic studies supported the existence of a unique vesicle-associated NTPPHase; apparent $K_{\mathrm{m}}(\mathrm{mM})$ of chondrocyte membrane NTPPHase was 1.5 and 3.0 at pH 7.3 and 9.88 , respectively; apparent $K_{\mathrm{m}}(\mathrm{mM})$ of vesicle associated NTPPHase was 0.83 and 1.28 at $\mathrm{pH} 7.3$ and 9.88. The data suggest the existence of a unique ectoNTPPHase associated with vesicles derived from normal articular cartilage. (J. Clin. Invest. 1995. 95:699-704.) Key words: nucleotide pyrophosphohydrolase - calcium pyrophosphate dihydrate $\cdot$ chondrocyte $\cdot$ vesicle $\cdot$ TGF $\beta_{1}$

Address correspondence to Dr. Ikuko Masuda, Division of Rheumatology, Medical College of Wisconsin, 8700 West Wisconsin Avenue, Milwaukee, WI 53226. Phone: 414-257-5587; FAX: 414-454-4040.

Received for publication 20 May 1994 and in revised form 11 October 1994.

J. Clin. Invest.

(c) The American Society for Clinical Investigation, Inc.

0021-9738/95/02/0699/06 \$2.00

Volume 95, February 1995, 699-704

\section{Introduction}

Calcium pyrophosphate dihydrate (CPPD) ${ }^{1}$ crystal deposition in human articular cartilage is a common age-dependent event often associated with degeneration of articular tissues and/or with acute attacks of arthritis $(1,2)$. Prospects for preventing or reversing CPPD crystal deposition depends on a better understanding of inorganic pyrophosphate $\left(\mathrm{PP}_{\mathrm{i}}\right)$ metabolism in joint tissues. Synovial fluid $\mathrm{PP}_{\mathrm{i}}$ levels are nearly always greater than those of plasma and correlate directly with the degree of radiographically evident joint degeneration (reviewed in reference 2 ). $P_{P_{i}}$ is released into the ambient medium when cartilage slices or isolated chondrocytes but not other joint tissues are cultured in vitro, suggesting that this tissue is the source of synovial fluid $\mathrm{PP}_{\mathrm{i}}$. Detergent extracts of CPPD crystal-encrusted degenerated cartilage contained increased nucleotide pyrophosphohydrolase (NTPPHase) activity relative to normal or degenerated cartilage without crystals (3). This enzyme generates $\mathrm{PP}_{\mathrm{i}}$ from ATP and other nucleotides. NTPPHase is an ectoenzyme in canine (4) and in human (5) chondrocytes. ATP levels were significantly higher in knee joint fluids containing CPPD crystals compared with fluids from osteoarthritis (217 vs. 98 $\mathrm{nM})$ (6) despite higher activity of NTPPHase in the former (7).

EctoNTPPHase activity is also associated with vesicles derived from chondrocytes in epiphyseal cartilage, termed matrix vesicles, and is thought by some investigators important for in vitro calcification $(8,9)$. Addition of ATP to vesicles isolated from adult porcine (10) or human (11) hyaline articular cartilage, termed articular cartilage vesicles (ACV), formed a mineral phase tentatively identified as monoclinic CPPD.

A sedimentable $127-\mathrm{kD}$ NTPPHase and soluble peptide fragments derived from it in porcine articular cartilage conditioned medium are described here. This enzyme is distinct from chondrocyte cell membrane NTPPHase and from PC-1, an ectoNTPPHase found in many types of cells $(12,13)$.

\section{Methods}

Materials. Thymidine monophosphate $p$-nitrophenyl ester (TMPNP), ATP from equine muscle, and yeast pyrophosphatase were from Sigma Chemical Co. (St. Louis, MO); $\left[{ }^{14} \mathrm{C}\right]$ uridine diphosphate glucose and $\left[{ }^{32} \mathrm{P}\right] \mathrm{PP}_{\mathrm{i}}$ were from ICN Biochemicals (Costa Mesa, CA); ${ }^{125} \mathrm{I}$ and enhanced chemiluminescence (ECL) kit was from Amersham (Arling-

1. Abbreviations used in this paper: $\mathrm{ACV}$, articular cartilage vesicles; anti-SNTP, anti-synthetic $\mathrm{NH}_{2}$-terminal $61-\mathrm{kD}$ soluble NTPPHase; $\mathrm{BCP}$, basic calcium phosphate; CPPD, calcium pyrophosphate dihydrate; EDC, 1-ethyl-3-(3-dimethylaminopropyl) carbodiimide hydrochloride; KPB, potassium phosphate buffer; NTPPHase, nucleotide triphosphate pyrophosphohydrolase; $\mathrm{PP}_{\mathrm{i}}$, inorganic pyrophosphate; $\mathrm{PSF}$, penicillin/streptomycin/Fungisone; TMPNP, thymidine monophosphate $p$-nitrophenyl ester. 
ton Heights, IL); ${ }^{125}$ I-protein A was prepared as described previously (14). DEAE-Sepharose resin, Mono Q HR5/5, Phenyl superose HR5/ 5 columns were from Pharmacia LKB Biotechnology Inc. (Piscataway, $\mathrm{NJ}$ ). Keyhole limpet hemocyanin, 1-ethyl-3-(3-dimethylaminopropyl) carbodiimide hydrochloride (EDC), Freund's complete and incomplete adjuvant Imject Immunogen EDC Conjugation Kit were from Pierce (Rockford, IL); TGF $\beta_{1}$ was from Austral Biologicals (San Ramon, CA); Affigel $102^{\mathrm{TM}}$ resin, protein A-horse radish peroxidase, Ampholyte, molecular weight, and isoelectric focusing standards were from Bio-Rad (Hercules, CA); FBS, PSF, DMEM, Hepes, and Hanks' balanced solution were from GIBCO (Grand Island, NY). Porcine cartilage was obtained from Johnsonville Sausage (Watertown, WI) and from Klement Sausage Co., Inc. (Milwaukee, WI).

Cartilage organ and chondrocyte monolayer cultures. Adult porcine articular cartilage was sliced from the femoral and patellar surfaces of knee joints with a scalpel under aseptic conditions shortly after slaughter. The cartilage was minced and incubated for $24 \mathrm{~h}$ in DMEM with $10 \%$ FBS and $1 \%$ penicillin/streptomycin/Fungisone (PSF). The cartilage was then washed, placed in serum-free DMEM containing $1 \%$ PSF, and incubated for up to $192 \mathrm{~h}$.

For monolayer cultures, chondrocytes were released from fresh cartilage by sequential digestion with trypsin and collagenase (15). Cells were plated at high density $\left(200,000\right.$ cells $\left./ \mathrm{cm}^{2}\right)$ and maintained as a primary culture in DMEM containing $10 \%$ FBS and 1\% PSF.

NTPPHase assay. Activity was measured using TMPNP as a substrate (16). Briefly, $100 \mu \mathrm{l}$ of enzyme was incubated at $37^{\circ} \mathrm{C}$ with 100 $\mu 12 \mathrm{mM}$ TMPNP, $50 \mathrm{mM}$ Hepes, pH 7.3, in Hanks' balanced salt solution. After $2 \mathrm{~h}, 800 \mu \mathrm{l}$ of $0.1 \mathrm{~N} \mathrm{NaOH}$ was added. Absorbance was determined at $410 \mathrm{~nm}$. Results are expressed as picomoles of substrate hydrolyzed per hour.

Enzyme activity was measured also using ATP as substrate as previously described (7). Briefly, using capped tubes, enzyme buffered with $50 \mathrm{mM}$ Tris acetate, $\mathrm{pH} 7.4$, containing trace $\left[{ }^{32} \mathrm{P}\right] \mathrm{PP}_{\mathrm{i}}$ and $1 \mathrm{mM}$ of sodium phosphate was incubated with $(a) 0.5 \mathrm{mM}$ ATP in $50 \mathrm{mM}$ Tris acetate, $(b)$ buffer only, or $(c) 0.5 \mathrm{mM}$ ATP in buffer containing yeast inorganic pyrophosphatase for $1 \mathrm{~h}$ at $37^{\circ} \mathrm{C}$. The tubes were placed in boiling water for $5 \mathrm{~min}$ to stop the reaction, cooled, centrifuged at $10,000 \mathrm{~g}$ for $5 \mathrm{~min}$, and the supernatant was stored at $-20^{\circ} \mathrm{C}$ for subsequent $\mathrm{PP}_{\mathrm{i}}$ measurement. Enzyme activity was calculated as $\mathrm{PP}_{\mathrm{i}}$ produced with or without added ATP. $P_{i}$ levels were measured using the $\left[{ }^{14} \mathrm{C}\right]$ UDPG radiometric method (17). These values were corrected for $\mathrm{PP}_{\mathrm{i}}$ hydrolysis by determining the percentage of ${ }^{32} \mathrm{P}$ precipitated as phosphomolybdate (18). Protein concentrations were determined by the Lowry et al. method (19) using BSA as standard.

Preparation of membrane fractions. Membrane fractions were isolated by a standard method (20) from homogenates of chondrocytes grown in primary monolayer culture for $4 \mathrm{~d}$. At this time, the ectoNTPPHase activity lost during chondrocyte release is fully reconstituted (21). The homogenate was centrifuged at $1,000 \mathrm{~g}$ for $15 \mathrm{~min}$, and the supernatant was centrifuged at $10,000 \mathrm{~g}$ for $1 \mathrm{~h}$. The pellet was resuspended in $50 \mathrm{mM}$ carbonate-bicarbonate buffer, $\mathrm{pH} 9.8$, containing $0.1 \%$ Triton X-100 and incubated for $1 \mathrm{~h}$ with constant shaking. This suspension was centrifuged at $10^{5} \mathrm{~g}$ for $1 \mathrm{~h}$, yielding solubilized membranederived protein. This supernatant fraction was used for further enzyme purification and for kinetic studies.

Purification of conditioned media. Cartilage organ cultures and chondrocyte monolayer conditioned media spontaneously release both soluble and sedimentable vesicle-associated NTPPHase (21). Conditioned media were harvested every $48 \mathrm{~h}$ and centrifuged at $10,000 \mathrm{~g}$ for $30 \mathrm{~min}$ to remove debris (all centrifugation was done at $4^{\circ} \mathrm{C}$ unless otherwise stated). The media was then centrifuged at $20,000 \mathrm{~g}$ for 10 min, $50,000 \mathrm{~g}$ for $60 \mathrm{~min}$, and finally at $2 \times 10^{5} \mathrm{~g}$ for $40 \mathrm{~min}$. The supernatant was used as the source of soluble enzyme, and the $2 \times 10^{5}$ $g$ pellet was used as the source of the sedimentable enzyme. This pellet contains a homogenous population of ACVs by electron microscopy (10). Alkaline phosphatase, 5' nucleotidase, and inorganic pyrophosphatase activities were measured in this pellet as described elsewhere (22).
Purification of soluble enzyme. The supernatant from ultracentrifuged conditioned medium was concentrated by ultrafiltration using 30,000 mol wt membranes (Centricell-60; Polyscience, Philadelphia, PA), dialyzed against $50 \mathrm{mM}$ Tris- $\mathrm{HCl}, \mathrm{pH} 9.0$, containing $1 \mathrm{mM} \mathrm{CaCl}_{2}$ and $1 \mathrm{mM} \mathrm{MgCl}$ (buffer A) at $4^{\circ} \mathrm{C}$ overnight, and applied to DEAESepharose columns $(1.5 \times 7.0 \mathrm{~cm})$ equilibrated with buffer A. Elution was carried out at $4^{\circ} \mathrm{C}$ by stepwise salt gradients of $0,0.1,0.2,0.3 \mathrm{M}$ $\mathrm{NaCl}$ in buffer A. Fractions were collected and assayed for protein and NTPPHase. The active fractions were pooled and concentrated using membrane cones (Centriflo-25A; Amicon, Beverly, MA). The concentrated enzymatically active eluate from the DEAE-Sepharose column was applied to an anion exchange column (FPLC-Mono Q, Pharmacia) in a high performance liquid chromatography system and equilibrated with buffer $\mathrm{A}$. The column was then eluted by a linear $(0-1 \mathrm{M} \mathrm{NaCl})$ salt gradient in buffer A (slope was $12.5 \mathrm{mM} / \mathrm{ml}$ ). 1-ml fractions were collected and assayed for protein and enzyme activity. The active fractions were pooled. The concentrated eluate from the Mono $\mathrm{Q}$ column was adjusted to $1.8 \mathrm{M}\left(\mathrm{NH}_{4}\right)_{2} \mathrm{SO}_{4}$ in $50 \mathrm{mM}$ potassium phosphate buffer (KPB), pH 9.0 (buffer B) and then immediately applied to a reverse phase column (FPLC-Phenyl Superose, Pharmacia) equilibrated with buffer $\mathrm{B}$. The column was then eluted by a linear desalting gradient between 1.8 and $0 \mathrm{M}\left(\mathrm{NH}_{4}\right)_{2} \mathrm{SO}_{4}$ in $50 \mathrm{mM} \mathrm{KPB}, \mathrm{pH} 9.0$ (slope of gradient was $51.4 \mathrm{mM} / \mathrm{ml}) ; 0.5 \mathrm{ml}$ fractions were collected, immediately desalted with $50 \mathrm{mM} \mathrm{KPB}, \mathrm{pH}$ 9.0, using Amicon membrane cones, and assayed for NTPPHase activity. The active fractions were again pooled and concentrated using Amicon cones. The final preparation was stored at $-70^{\circ} \mathrm{C}$. The enzyme activity was very labile in the presence of prevailing salt concentration. It was therefore necessary to proceed with these last steps immediately. Molecular mass was determined from the comparative relative mobilities of standards on SDSPAGE (23).

Characterization of soluble enzyme. (a) Kinetic studies and $\mathrm{pH}$ optima were performed for both the vesicle-associated and plasma membrane-associated enzyme using TMPNP as a substrate. $V_{\max }$ and $K_{\mathrm{m}}$ were determined at $\mathrm{pH} 7.31$ and 9.88 for both enzymes using standard methods (24). The activity of the soluble fragment against ATP and TMPNP was determined in fractions eluted from the Mono $Q$ column. (b) The $\mathrm{NH}_{2}$ terminal amino acid sequence of the purified protein was determined by the Protein and Nucleic Acid Facility of the Medical College of Wisconsin Cancer Center after SDS-PAGE resolution and transblotting to polyvinylidene difluoride membrane (Immobilon- $\mathrm{P}^{\mathrm{TM}}$ transfer membrane, Millipore Corp., Burlington, MA). The 61-kD band was cut out and applied to gas phase protein sequencer (Applied Biosystems $477 \mathrm{~A}^{\mathrm{TM}}$ ). A $26 \mathrm{NH}_{2}$-terminal amino acid sequence was referred to the NBRF sequence databank for homology with known protein structures.

Production of antibodies and affinity purification. A peptide corresponding to the first $15 \mathrm{NH}_{2}$-terminal amino acids was synthesized by a solid-phase method using N-Fmoc-amino acids (25). This peptide was purified by HPLC and its composition confirmed by amino acid analysis. The synthetic peptide was covalently coupled to keyhole limpet hemocyanin using EDC and an Imject Immunogen EDC Conjugation Kit. The degree of peptide incorporation into the carrier was estimated by HPLC comparing the peaks before and after conjugation. Synthetic peptide-carrier protein conjugate was injected subcutaneously into three 1 -yr-old New Zealand White male rabbits, using an equal volume mixture of immunogen with Freund's complete adjuvant. Booster injections in Freund's incomplete adjuvant were given every 2 wk thereafter. Antibody titer was determined by Western blots of peptide in doubling dilutions (14) using either ECL or ${ }^{125}$ I-protein A autoradiography for visualization.

The synthetic peptide was coupled to Affi-gel $102^{\mathrm{TM}}$ (Bio-Rad) using the EDC and then equilibrated with PBS. Immune serum was loaded slowly onto the peptide affinity column, rinsed with PBS, and eluted with $0.1 \mathrm{M}$ glycine $\mathrm{HCl}$ buffer, $\mathrm{pH} 2.8$. This affinity purified IgG antibody [anti-synthetic $\mathrm{NH}_{2}$-terminal $61-\mathrm{kD}$ soluble NTPPHase (antiSNTP)] was neutralized immediately with $1 \mathrm{M} \mathrm{KPB}, \mathrm{pH}$ 9.3. Antibody was concentrated and buffer exchanged with PBS using Amicon cones. 
Immunoprecipitation. The purified antibody was incubated for $2 \mathrm{~h}$ at $4^{\circ} \mathrm{C}$ with partially purified NTPPHase (after Mono $\mathrm{Q}$ step) in the presence of $1 \% \mathrm{BSA}$ to reduce nonspecific absorption. After $2 \mathrm{~h}$ at $4^{\circ} \mathrm{C}$, Sephadex beads coupled with protein A were added, mixed for $2 \mathrm{~h}$, and centrifuged at $12,000 \mathrm{~g}$ for $10 \mathrm{~min}$.

Western blot. Anti-SNTP in a dilution of 1:7,000 was used in Western blots against $1 \%$ SDS extracts from each of the following: (a) porcine chondrocytes in monolayer culture harvested and washed twice with PBS, $(b)$ subcellular fractions prepared from such chondrocytes (20), (c) ACV from enzymatically digested cartilage (10), (d) washed $2 \times 10^{5} \mathrm{~g}$ pellets of porcine cartilage organ culture conditioned medium containing $\mathrm{ACV},(e)$ whole porcine cartilage, $(f)$ washed cultured human skin fibroblasts, $(g)$ human knee joint fluid from a patient with severe degeneration and CPPD crystal deposition, $(h)$ plasmacytoma cell lysate as a PC-1 antigen marker (kindly provided by Scott Hickman, Washington University, St. Louis, MO).

A rabbit polyclonal antibody raised against recombinant mouse plasmacytoma PC-1, also obtained from Dr. Hickman, was tested against purified 61-kD NTPPHase and against chondrocyte membrane preparations exhibiting NTPPHase activity. The antibody was used at a dilution of $1: 10,000$

Each minigel $(7 \times 8 \mathrm{~cm} \times 0.75 \mathrm{~mm} 8 \%$ SDS $)$ lane was loaded with 10-15 $\mu \mathrm{g}$ protein; up to $240 \mu \mathrm{g}$ protein was loaded per lane using larger ( $16 \times 16 \mathrm{~cm} \times 1.5 \mathrm{~mm} 8 \%$ SDS $)$ gels. Anti-SNTP used routinely at 1:50,000. To detect antigen in 1\% SDS extract of chondrocyte lysate, it was used at a dilution of 1:5,000. The method could detect about

NTPPHase activity of Monoan fractions
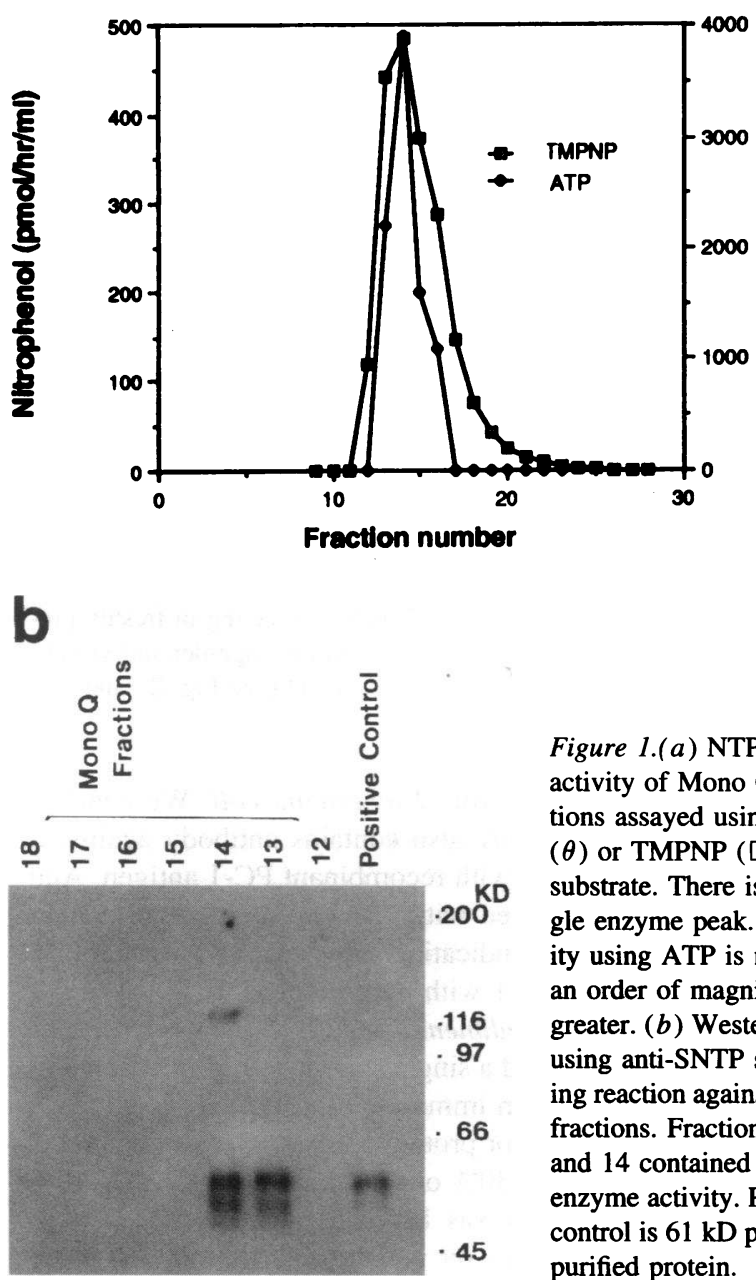

Figure 1.(a) NTPPHase activity of Mono $Q$ fractions assayed using ATP $(\theta)$ or TMPNP $(\square)$ as substrate. There is a single enzyme peak. Activity using ATP is nearly an order of magnitude greater. (b) Western blot using anti-SNTP showing reaction against these fractions. Fraction 13 and 14 contained peak enzyme activity. Positive control is $61 \mathrm{kD}$ partially purified protein.
Table I. Kinetic Studies Using Chondrocyte Membrane and Sedimentable (Vesicle) Enzyme*

\begin{tabular}{cccc}
\hline & & & Apparent \\
$\mathrm{pH}$ & & $V_{\max }$ & $K_{\mathrm{m}}$ \\
\hline & & pmolh per $m l$ & $m M$ \\
& & 0.658 & 1.50 \\
7.31 & Membrane sedimentable $(127 \mathrm{kD})$ & 0.012 & 3.00 \\
& & 0.677 & 0.83 \\
9.88 & Membrane sedimentable & 0.542 & 1.28
\end{tabular}

* TMPNP was used at $0.2,0.5,1.0$, and $2.0 \mathrm{mM}$. Incubation was at 10 , 20,30 , and $60 \mathrm{~min}$ at $37^{\circ} \mathrm{C} ; 800 \mu \mathrm{l}$ of $0.1 \mathrm{~N} \mathrm{NaOH}$ was added to stop the reaction.

$0.015 \mu \mathrm{g}$ antigen using the large gels. Thus antigen in concentrations $<0.006 \%$ of protein would not be detected.

Purification of sedimentable enzyme. The $2 \times 10^{5} \mathrm{~g}$ pellet from conditioned media, containing ACV, was dialyzed against a large volume of $50 \mathrm{mM}$ Tris- $\mathrm{HCl}, \mathrm{pH} 6.8$, for $4 \mathrm{~h}$ at $4^{\circ} \mathrm{C}$ and then dissolved in SDS sample buffer ( $1 \%$ SDS, $10 \%$ glycerol, $50 \mathrm{mM}$ Tris- $\mathrm{HCl}, \mathrm{pH} 6.8$, and $\beta$-mercaptoethanol). The proteins were separated on a 3-mm-thick preparative SDS-PAGE gel. SNTP was visualized by Western blot from a test strip sliced from this gel. After the staining of the preparative gel with Coomassie brilliant blue, this band was cut out, sliced, and electroeluted (model 422 Elect-eluter, Bio-Rad). The electroeluted protein was lyophilized, stored at $-70^{\circ} \mathrm{C}$, and used as a marker for immunoblots. A sample of the electroeluted protein was subjected to twodimensional gel analysis (26).

Preparation of $A C V$ fractions. Vesicles were isolated from porcine articular cartilage by sequential digestion with hyaluronidase, trypsin, and collagenase (10). The cartilage digest was then treated as described for conditioned media. The pellet from the $2 \times 10^{5} \mathrm{~g}$ centrifugation contained numerous vesicles by electron microscopy (10). ACV fractions were also obtained from 72 -h conditioned media of primary monolayer chondrocyte cultures using the same procedure described for cartilage-conditioned media. ACV containing fractions were prepared from conditioned media of cultured chondrocyte with and without TGF $\beta_{1}$ [10 $\mathrm{nM}$ final concentration, a level that increases $\mathbf{P P}_{\mathrm{i}}$ production by chondrocytes $(27,28)]$.

\section{Results}

Purification and partial characterization of soluble enzyme. Soluble NTPPHase from cartilage organ cultures was purified more than 3,000 -fold over the supernatant of $2 \times 10^{5} \mathrm{~g}$ conditioned media. The specific activity and yield of the enzyme were typically $2.5 \times 10^{5} \mathrm{U} / \mathrm{mg}$ of protein and $5 \%$, respectively. Throughout purification with Mono Q and Phenyl Superose, a single peak of NTPPHase activity was seen. On a $8 \%$ polyacrylamide gel, the purified protein in $1 \%$ SDS migrated as a single band with an estimated molecular mass of $61 \mathrm{kD}$. NTPPHase activity of the $61-\mathrm{kD}$ protein from Mono $\mathrm{Q}$ fractions using excess ATP or TMPNP as substrate is shown in Fig. $1 a$. Activity using ATP as a substrate was nearly an order of magnitude greater. Western blot of these fractions using antibody to the synthetic peptide (anti-SNTP) is shown in Fig. $1 b$.

Kinetic analyses of NTPPHase activity of the solubilized chondrocyte membrane and sedimentable (ACV) NTPPHase are given in Table I. Substrate-velocity plots yielded straight lines in all experiments. The $\mathrm{pH}$ optimum for both enzyme activities was 9.88. The first $26 \mathrm{NH}_{2}$-terminal amino acids from 
Table II. Partial Amino Acid Sequence of Purified Soluble NTPPHase

$\mathrm{NH}_{2}$-Glu-Asp-Arg-Thr-Phe-Leu-Val-Gly-Asn-Met-Glu-Arg-ArgThr-X-Leu-Phe-Asn-Leu-Asp-Val-Pro-Ala-Thr-Arg-X-

Done at MCW sequencing facility directed by L. Minde-Muller, Ph.D. $\mathrm{X}$, not determined.

the single $61-\mathrm{kD}$ band on SDS-PAGE transblotted to PVDF transfer membrane were obtained (Table II). There was no significant $(<30 \%)$ homology with any known protein, including PC-1, an NTPPHase whose complete sequence is known (29). A peptide (1,837 mol wt) was synthesized corresponding to the first $15 \mathrm{NH}_{2}$-terminal amino acids; $263 \mathrm{mg}$ was made at $74 \%$ yield. Its amino acid composition, HPLC mobility, and magnetic resonance analysis confirmed that the original peptide had been reproduced.

Production of antibodies. All three rabbits made antibodies to the synthetic peptide (anti-SNTP) as measured by Western blot using the peptide as antigen. These antibodies reacted with both the crude preparation (mainly $127 \mathrm{kD}$ ) and the purified soluble $61-\mathrm{kD}$ enzyme.

Immunoprecipitation. Anti-SNTP failed to precipitate native $61-\mathrm{kD}$ soluble NTPPHase, even after affinity purification. Covalently coupling the affinity purified antibody directly to Sephadex beads also failed to remove detectable amounts of NTPPHase activity.

Immunoreactivities against synthetic $\mathrm{NH}_{2}$ terminal 61-kD soluble NTPPHase antibody (anti-SNTP) using Western blot. (a) Porcine chondrocytes and their $(b)$ subcellular fractions: Anti-SNTP failed to recognize any protein in a $1 \%$ SDS lysate of washed chondrocytes harvested after $4 \mathrm{~d}$ in primary monolayer culture, nor did this antibody recognize any protein in plasma membrane preparations prepared from such chondrocytes. (c) ACV from enzymatically digested cartilage: a 61-kD protein was recognized by anti-SNTP (Fig. 2, lane 1 ). (d) NTPPHase in cartilage conditioned media $2 \times 10^{5} \mathrm{~g}$ pellets: A strong $127-\mathrm{kD}$ reactivity was found in $1 \%$ SDS extracts of pelleted ACV (Fig. 2, lanes 2 and 3). A series of reactivities was found in the conditioned media supernatant also, ranging from 127 to below $50 \mathrm{kD}$, including a $61-\mathrm{kD}$ band representing our original purification. (e) Whole cartilage: 1\% SDS extracts of porcine cartilage reacted with anti-SNTP, which recognized a 127-kD band most intensely (Fig. 3, lane 5, and Fig. 4, lane 4). $(f)$ Human skin fibroblasts: Anti-SNTP failed to react against a $1 \%$ SDS extracts of washed cultured adult human skin fibroblasts. $(g)$ Human joint fluid: $1 \%$ SDS extracts of synovial fluid from a patient with severe knee joint degeneration associated CPPD crystal deposition disease reacted with anti-SNTP (Fig. 4, lane 1). (h) Plasmacytoma cell lysate: anti-SNTP showed no reactivity against this preparation, known to contain PC-1 antigen.

Anti-PC-1 antibody showed reactivity against a $115-\mathrm{kD}$ protein in the plasmacytoma cell lysate used as positive control (Fig. 5, lane 7) and against a $115-\mathrm{kD}$ protein in a porcine chondrocyte membrane preparation (Fig. 5, lane 5) but not against fractions of NTPPHase activity elevated from a Mono $Q$ column (Fig. 5, lanes 2 and 3). Anti-PC-1 antibody consistently reacted against $\beta$-galactosidase high molecular weight marker.

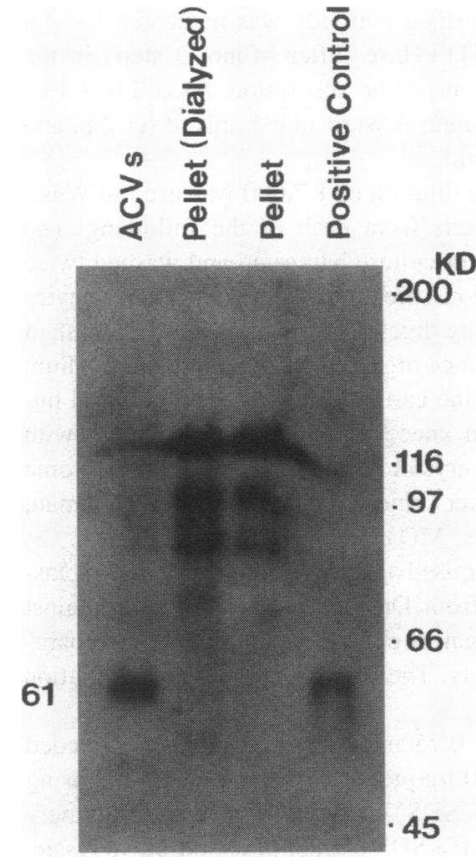

Figure 2. Western blot showing reaction of antiSNTP against $1 \%$ cartilage conditioned media $2 \times 10^{5}$ $g$ pellet in lanes 2 and 3 and against ACSs freshly liberated from articular cartilage using digestive enzymes in lane 1 . The $61-\mathrm{kD}$ purified protein is used here as a positive control.
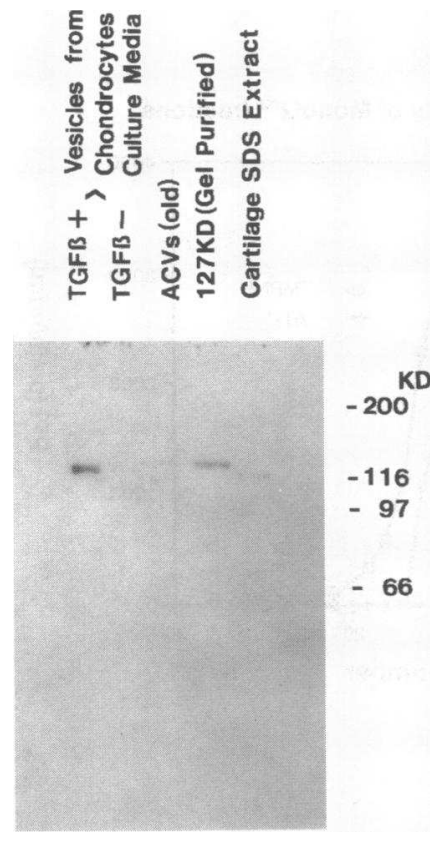

Figure 3. Western blot showing reaction against vesicles from TGF $\beta_{1}$ stimulated chondrocyte monolayer culture medium in lane 1 , control culture medium without $\operatorname{TGF} \beta_{1}$ in lane 2 , a vesicle preparation from ACVs stored at $-20^{\circ} \mathrm{C}$ for $30 \mathrm{~d}$ in lane 3 , electroeluted gel purified 127 . $\mathrm{kD}$ protein in lane 4 , and whole cartilage $1 \%$ SDS extract in lane 5. It is likely that intact NTPPHase is degradated by the trypsin used to liberate the vesicles from the cartilage matrix as the major protein reacting in freshly prepared cartilage-derived vesicles is $61 \mathrm{kD}$ (see Fig. 2, lane 1).

This protein was derived from Escherichia coli. We conclude that the anti PC-1 antibody also contains antibody against $\beta$ galactosidase co-purified with recombinant PC-1 antigen. AntiPC-1 antibody also reacted with $1 \%$ SDS extracts of porcine skin or whole cartilage, indicating cross-reactivity of antibody raised against mouse $\mathrm{PC}-1$ with porcine $\mathrm{PC}-1$.

Characterization of sedimentable 127- $k D$ enzyme. The electroeluted protein produced a single spot on two-dimensional gel analysis. Fig. $6 a$ shows an immunoblot using anti-SNTP and $b$ shows an India ink stain for protein on the transblotted nitrocellulose membrane. About $30 \%$ of total protein in the $2 \times 10^{5} \mathrm{~g}$ pellet (ACV preparation) was 127 kD NTPPHase.

Marker enzyme studies on vesicle preparation. All values 


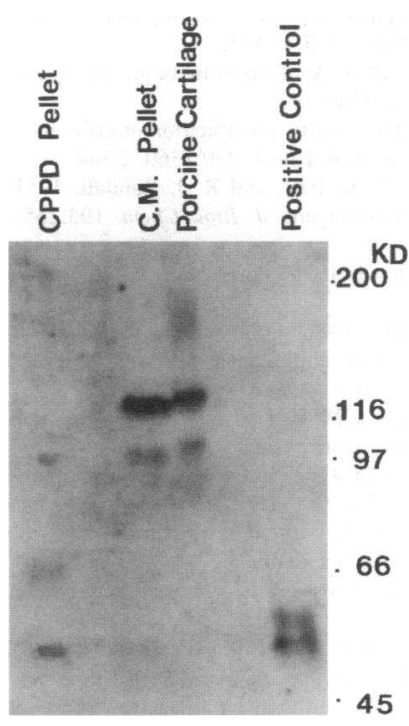

Figure 4. Western blot of $1 \%$ SDS extract of CPPD joint fluid pellet shown in lane 1 . Lanes 3 and 4 contain $1 \%$ SDS extract of porcine cartilage conditioned medium $2 \times 10^{5} \mathrm{~g}$ pellet and whole cartilage, respectively; lane 6 contains control $61-\mathrm{kD}$ fragment; lanes 2 and 5 are vacant.

are given as mean $\pm \mathrm{SD}, n=3$. Alkaline phosphatase, 1,310 $\pm 57 \mathrm{nmol}$ nitrophenyl $\mathrm{min}^{-1} \mathrm{mg}$ protein ${ }^{-1} ; 5^{\prime}$ nucleotidase, $0.21 \pm 0.02 \mu \mathrm{mol} \mathrm{NAD} \min ^{-1} \mu \mathrm{g}$ protein ${ }^{-1}$; inorganic pyrophosphatase, $3.6 \pm 0.01 \mathrm{nmol} \mathrm{Pi} \mathrm{min}^{-1} \mathrm{mg}$ protein ${ }^{-1}$; NTPPHase, $189 \pm 6 \mathrm{fmol}$ nitrophenol $\mathrm{min}^{-1} \mu \mathrm{g}$ protein ${ }^{-1}$.

Effect of TGF $\beta_{1}$ on sedimentable (ACV) NTPPHase. Reactivity against anti-SNTP was easily detectable in Western blots using a $1 \%$ SDS extract of conditioned media pellets prepared from chondrocytes exposed to $10 \mathrm{nM}$ TGF $\beta_{1}$ (Fig. 3, lane 1). The electroeluted $127-\mathrm{kD}$ protein (positive control) is shown in Fig. 3, lane 4. A conditioned media pellet from cells without added $\operatorname{TGF} \beta_{1}$ is shown in Fig. 3, lane 2. Sedimentable NTPPHase activity using TMPNP as substrate was increased three- to sevenfold by TGF $\beta_{1}$.

\section{Discussion}

The ectoNTPPHase associated with ACV appears to be a unique protein based on its $\mathrm{NH}_{2}$-terminal amino acid sequence, its kinetic parameters, and the failure of a highly purified specific antibody raised against it to recognize PC-1, an NTPPHase ectoenzyme found originally in a plasmacytoma (12) and pres-

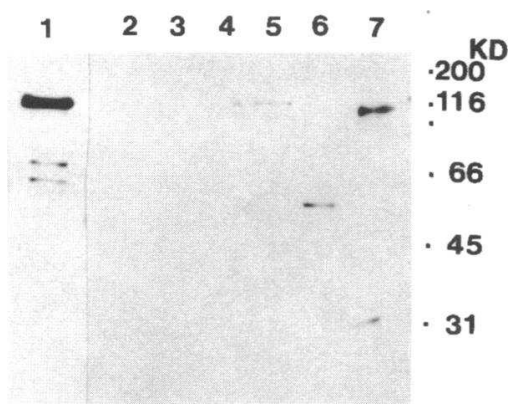

Figure 5. Western blot using PC-1 antibody against pig chondrocyte membrane-bound NTPPHase. Lane 1, high molecular weight marker-PC-1 antibody consistently reacted to $116-\mathrm{kD} \beta$ galactosidase. Lanes 2 and 3, fractions with peak enzyme activity Mono Q column.

Chromatography showing no reaction. Lane 4, peak enzyme fraction from gel filtration column chromatography showing a weak $115-\mathrm{kD}$ band. Lane 5 , membrane fraction from chondrocyte homogenate showing a weak $115-\mathrm{kD}$ band. Lane 6 , whole pig chondrocyte homogenate showing a very weak 115 - and a $60-\mathrm{kD}$ band were shown. Lane 7, PC1 positive control.
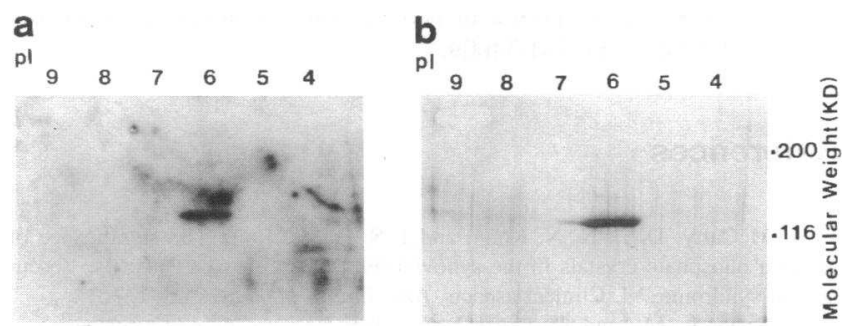

Figure 6. (a) Western blot showing reaction against two-dimensional gel separation of electroeluted $127-\mathrm{kD}$ protein. The smudge above the $127-\mathrm{kD}$ protein is an artefact. (b) A single protein was stained by India ink. The elongated pattern shows charge heterogeneity.

ent in many cell types in many species (29-31). Antibody to the ACV enzyme recognized both soluble and sedimentable proteins in human synovial fluid and in vesicles derived from porcine articular cartilage conditioned media. Synovial fluid appears to resemble conditioned medium from cartilage organ culture in its content of both soluble and ACV associated (sedimentable) enzyme.

Ali (32) first demonstrated vesicles in degenerating human cartilage and showed that some of them were associated with apatite mineral. Gordon et al. (33) correlated cartilage calcification with the degree of severity of osteoarthritis, and we also found a correlation between the content of basic calcium phosphate (BCP) mineral in synovial fluid (carbonate-apatite and octacalcium phosphate) and the degree of radiologic degenerative change $(34,35)$. The release of the $127-\mathrm{kD}$ NTPPHase may be a marker for increased vesicle formation by chondrocytes. The $127-\mathrm{kD}$ enzyme appears to undergo proteolytic degradation in synovial fluid and, to a lesser extent, in cartilage organ culture conditioned medium. The precise role and relative importance of vesicle-associated ectoNTPPHase, of PC-1, and possibly of other ectoenzymes in the metabolism of extracellular ATP (6) remains to be defined. ATP-enhanced in vitro mineralization has been demonstrated in matrix vesicles from growth plate cartilage ( 8 ). The product mineral was largely dependent on generation of $\mathrm{PP}_{\mathrm{i}}$ from ATP. This same mineral may be pathologic when present in fluids from degenerated joints. BCP crystals stimulate synovial cell proliferation as well as synthesis and secretion of matrix-degrading neutral proteases $(36,37)$. In isolated ACV from adult osteoarthritic human and normal porcine cartilage, NTPPHase was needed for generation of CPPD crystals (10). ATP-induced CPPD crystal formation by ACV was abolished by incubation with pyrophosphatase and was inhibited by substitution of ATP analogues that could not be degraded to $\mathrm{PP}_{\mathrm{i}}$, indicating that generation of $\mathrm{PP}_{\mathrm{i}}$ from ATP was necessary. When ATP was added to porcine cartilage organ cultures, mineral formed in vesicular structures adjacent to chondrocytes (11). ACV containing NTPPHase are present in all adult articular cartilages. Further study of ACV-associated NTPPHase may offer new insights into the mechanism of pathologic BCP and CPPD mineral formation.

\section{Acknowledgments}

We gratefully acknowledge Dr. B. A. Derfus for providing cartilage derived vesicles and for helpful suggestions. We also thank Dr. L. Minde-Müller and her staff in MCW Protein and Nucleic Acid Facility for expert technical collaboration. We thank Klement's packing plants and Johnsonville packing plants for providing tissues. 
This work was supported in part by National Institutes of Health grants AR-38656 and GM-34009.

\section{References}

1. McCarty, D. J., N. N. Kohn, and J. S. Faires. 1962. The significance of calcium phosphate crystals in the synovial fluid of arthritis patients: the "pseudogout syndrome." I. Clinical aspects. Ann. Intern. Med. 56:711-737.

2. Ryan, L. M., and D. J. McCarty. 1993. Calcium pyrophosphate crysta deposition disease (pseudogout; articular chondrocalcinosis). In Arthritis and Allied Conditions. 12th. ed. D. J. McCarty and W. J. Koopman, editors. Lea \& Febiger, Malvern, Philadelphia. 1835-1855.

3. Tenenbaum, J. O., O. Muniz, H. R., Schmacher, A. E. Good, and D. S Howell. 1981. Comparison of phosphohydrolase activities from articular cartilage in calcium pyrophosphate deposition disease and primary osteoarthritis. Arthritis Rheum. 24:294-300.

4. Ryan, L. M., R. L. Wortmann, B. Karas, and D. J. McCarty. 1984. Cartilage nucleoside triphosphate (NTP) pyrophosphohydrolase. I. Identification as an ectoenzyme. Arthritis Rheum. 27:404-409.

5. Caswell, A. M., and R. G. G. Russell. 1985. Identification of ecto-nucleoside triphosphate pyrophosphatase in human articular cartilage in monolayer culture. Biochem. Biophys. Acta. 847:40-47.

6. Ryan, L. M., J. W. Rachow, and D. J. McCarty. 1991. Synovial fluid ATP a potential substrate for the production of inorganic pyrophosphate. J. Rheumatol. 18:716-720.

7. Rachow, J. W., and L. M. Ryan. 1985. Adenosine triphosphate pyrophosphohydrolase and neutral inorganic pyrophosphatase in pathologic joint fluids Arthritis Rheum. 28:1283-1288.

8. Siegel, S. A., C. F. Hummel, and R. P. Carty. 1983. The role of nucleoside triphosphate pyrophosphohydrolase in in vitro nucleoside triphosphate dependen matrix vesicle calcifications. J. Biol. Chem. 258:8601-8607.

9. Caswell, A. M., S. Y. Ali, and R. G. G. Russell. 1987. Nucleoside triphosphate pyrophosphatase of rabbit matrix vesicles, a mechanism in the generation of inorganic pyrophosphate in epiphyseal cartilage. Biochem. Biophys. Acta. 924:276-283

10. Derfus, B. A., J. W. Rachow, N. S. Mandel, A. L. Boskey, M. Buday, V. M. Kushnaryyov, and L. M. Ryan. 1992. Articular cartilage vesicles generate calcium pyrophosphate dihydrate-like crystals in vitro. Arthritis Rheum. 35:231 240.

11. Ryan, L. M., I. V. Kurup, B. A. Derfus, and V. M. Kushnaryyov. 1992 ATP-induced chondrocalcinosis. Arthritis Rheum. 35:1520-1525.

12. Rebbe, N. F., B. D. Tong, E. M. Finley, and S. Hickman. 1991. Identification of nucleotide pyrophosphatase/alkaline phosphodiesterase I activity associated with the mouse plasma cell differentiation antigen PC-1. Proc. Natl. Acad. Sci. USA. 88:5192-5196.

13. Rebbe, N. F., B. D. Tong, and S. Hickman. 1993. Expression of nucleotide pyrophosphatase and alkaline phosphodiesterase I activities of PC-1, the murine plasma cell antigen. Mol. Immunol. 30:87-93.

14. Haas, A. L., and P. M. Bright. 1985. Immunochemical detection and quantitation of intracellular ubiquitin protein conjugates. J. Biol. Chem 260:12464-12473.

15. Cheung, H. S., and L. M. Ryan. 1981. A method of determining DNA and chondrocyte content of articular cartilage. Anal. Biochem. 116:93-97.

16. Rachow, J. W., L. M. Ryan, D. J. McCarty, and P. B. Halverson. 1988. Synovial fluid inorganic pyrophosphate concentration and nucleotide pyrophos- phoydrolase activity in basic calcium phosphate deposition arthropathy and Milwaukee Shoulder Syndrome. Arthritis Rheum. 31:408-413.

17. Cheung, C. P., and R. J. Suhadolnik. 1977. Analysis of inorganic pyrophosphate at the picomole level. Anal. Biochem. 83:61-63.

18. Sugino, Y., and Y. Miyoshi. 1964. The specific precipitation of orthophosphate and some biochemical applications. J. Biol. Chem. 239:2360-2364.

19. Lowry, O. H., N. J. Rosebrough, A. L. Farr, and R. J. Randall. 1951 Protein measurements with the Folin phenol reagent. J. Biol. Chem. 193:265275

20. Thomas, T. C., and M. G. McNamee. 1990. Purification of membrane proteins. Methods Enzymol. 182:499-520.

21. Rachow, J. W., and D. J. McCarty. 1986. Spontaneous solubilization of ecto-nucleoside pyrophosphohydrolase from cultured articular cartilage and chondrocytes. Arthritis Rheum. 29:S15. (Abstr.)

22. Ryan, L. M., R. L. Wortmann, B. Karas, M. P., Lynch, and D. J. McCarty 1986. Pyrophosphohydrolase activity and inorganic pyrophosphate content of cultured human skin fibroblasts: elevated levels in some patients with calcium pyrophosphate dihydrate deposition disease. J. Clin. Invest. 77:1689-1693.

23. Laemmli, U. K. 1970. Cleavage of the structural proteins during the assembly of the head of bacteriophage T4. Nature (Lond.) 227:680-685.

24. Bell, J. E., and E. T. Bell. 1988. Proteins and Enzymes. Prentice Hall, Englewood Cliffs, NJ. 499 pp.

25. Stewart, J. M., and J. D. Young. 1984. Solid Phase Peptide Synthesis 2nd. ed. Pierce Chemical Co., Rockford, IL. 135 pp.

26. O'Farrel, P. H. 1975. High resolution two-dimensional electrophoresis of proteins. J. Biol. Chem. 250:40007-40021.

27. Rosenthal, A. K., H. S. Cheung, and L. M. Ryan. 1991. Transforming growth fact $\beta 1$ stimulates pyrophosphate elaboration by porcine cartilage. Arthritis Rheum. 34:904-911.

28. Rosenthal, A. K., B. A. McCarty, H. S. Cheung, and L. M. Ryan. 1993 A comparison of the effect of transforming growth factor beta 1 on pyrophosphate elaboration from various articular tissues. Arthritis Rheum. 36:539-542.

29. Funakoshi, I., H. Kato, K. Horie, T. Yano, Y. Hori, H. Kobayshi, T. Inoue, H. Suzuki, S. Fukui, M. Tsukahara, et al. 1992. Molecular cloning of cDNAs for human fibroblast nucleotide pyrophosphatase. Arch. Biochem. Biophys. 295:180187.

30. Takahashi, T., L. J. Old, and E. A. Boyse. 1970. Surface alloantigens of plasma cells. J. Exp. Med. 131:1325-1341.

31. Harahap, A. R., and J. W. Goding. 1988. Distribution of the murine plasma cell antigen PC-1 in non-lymphoid tissue. J. Immunol. 141:2317-2320.

32. Ali, S. Y. 1977. Matrix vesicles and apatite nodules in arthritic cartilage. In D. A. Willoughby; Perspectives in Inflammation, J. P. Giroud, G. P. Velo, editors. MTP Press, Lancaster, UK. 211-223.

33. Gordon, G. V., T. Villanueva, H. R. Schumacher, and V. Gohel. 1984. Autopsy study correlating degree of osteoarthritis, synovitis and evidence of articular calcification. J. Rheumatol. 11:681-686.

34. Halverson, P. B., and D. J. McCarty. 1979. Identification of hydroxyapatite crystals in synovial fluid. Arthritis Rheum. 22:389-395.

35. Halverson, P. B., and D. J. McCarty. 1986. Patterns of radiographic abnormalities associated with basic calcium phosphate and calcium pyrophosphate dihydrate crystal deposition in the knee. Ann. Rheum. Dis. 45:603-605.

36. Cheung, H. S., and L. M. Ryan. 1993. Role of crystal deposition in matrix degradation. In Joint Cartilage Degradation: Basic Research and Clinical Implications. F. Woessner and D. S. Howell, editors. Marcel Dekker, Inc., New York. 209-223.

37. Halverson, P. B., and D. J. McCarty. 1993. Basic calcium phosphate (apatite, octacalcium phosphate, tricalcium phosphate) crystal deposition disease. In Arthritis and Allied Conditions. 12th ed. D. J. McCarty and W. J. Koopman, editors. Lea \& Febiger, Malvern/Philadelphia. 1857-1872. 